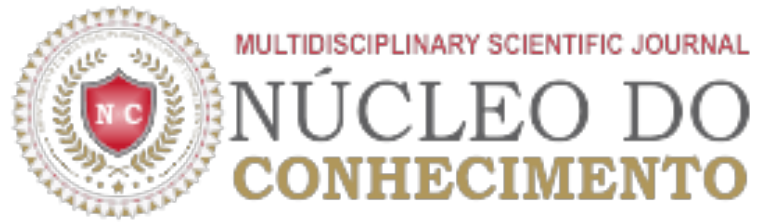

\section{The Role of Nursing in the Hemodialysis Session}

ROCHA, Maria Tereza Ferreira Barros [1]

OLIVEIRA, Ciane Martins de [2]

FECURY, Amanda Alves [3]

DENDASCK, Carla Viana [4]

DIAS, Cláudio Alberto Gellis De Mattos [5]

OLIVEIRA, Euzébio de [6]

ROCHA, Maria Tereza Ferreira Barros; et.al. The Role of Nursing in the Hemodialysis Session. Multidisciplinary Scientific Journal. Special Edition of Health. Year 02, Issue 11, Vol. 04. pp. 39-52, November 2017. ISSN:2448-0959

\begin{abstract}
This study considers important mechanisms regarding the role of the nurse in the hemodialysis session. It also aims, according to the bibliographic reference, to show common complications in this segment. The study aims to identify and recognize the importance of nursing in the hemodialysis session. The research was based on a bibliographical study and articles. The results indicate that in the hemodialysis session the role of nurses includes, among other aspects, prevention through patient orientation, in order not to aggravate or further compromise the situation. This type of contact through dialogue between the nurse and the patient is of fundamental importance, since there is an occurrence in which the patient suffers from multiple alterations, thus requiring the presence of this professional. With this, it is concluded that the implementation of a counseling, education and patient care work, besides allowing the nurse to perform the previous diagnosis, can avoid possible complications in the hemodialysis session.
\end{abstract}

Keywords: Hemodialysis, Patient, Nurse, Education.

\section{INTRODUCTION}


The kidneys are responsible for eliminating waste from the digestion of food after the body has taken advantage of all its nutrients. When the kidneys are not working properly, it is necessary to make diet adjustments so that the body does not become overloaded with these wastes (ELIZA, 2009).

This measure is considered important so that the problem in the kidneys does not generate future Chronic Kidney Failure (CRF).

Chronic Renal Insufficiency (CRF) refers to the progressive and irreversible loss of renal function. If there is no treatment, it will lead to death. CRF can be treated by hemodialysis in selected patients, whose main criterion is to have a stable cardiac function (DALGIRDAS, 2003).

In view of the above, this article reveals its importance in approaching this theme in which it highlights the role of the nurse in the hemodialysis session.

The hemodialysis sessions belong to the area of ??nephrology that presents a wide and diversified knowledge. And it is in this sense that we seek here to demonstrate what the role and importance of the nurse in the face of the patient who is in the process of hemodialysis is really.

Hemodialysis is the process of filtering and purifying the blood of undesirable substances such as creatinine and urea that need to be eliminated from the human blood stream due to deficiency in the filtration mechanism in patients with CRF. In hemodialysis, the transfer of solutes occurs between the blood and the dialysis solution through a membrane.

In this sense, the role of nurses to better perform it, appropriates the Nursing Assistance Systematization (SAE), basically to be able to apply knowledge in patient care and characterize their professional practice, contributing in the definition of their function in the best way possible.

Thus, this study may bring benefits and contributions to nurses, especially the nephrologist, since it will highlight their role during hemodialysis sessions, thus demonstrating their importance for a better treatment.

In view of this context, this article aimed to identify the role of nurses in the hemodialysis session, considering their attributions to the patient.

\section{THEORETICAL REFERENCE}

According to Riella (2001) it is understood as hemodialysis, a process in which an artificial kidney (hemodialyzer) is used to purify the blood.

Therefore, it is understood that the person who loses his renal function in a chronic way, should be assisted and be advised to undergo the hemodialysis treatment. Thus, hemodialysis will replace the function of the kidneys, purifying the blood plasma by means of a filter attached to an artificial kidney - a hemodialysis machine (RIELLA, 2001).

It is found that in this treatment patients become dependent on this machine to survive, as it performs damaged kidney function by filtering and eliminating blood impurities such as urea, creatinine and excess 
fluid (RIELLA, 2001).

During the hemodialysis session, two needles are inserted into the fistula, one to send the blood to the hemodialyzer, which is a kind of filter, and the other to return it to the patient (RIELLA \& MARTINS, 2001).

The duration and frequency of hemodialysis sessions will be established according to the amount of dialysis required for the patient to obtain the largest possible clearance of solutes, to maintain hydroelectrolytic and acid-base balance, to control blood pressure and nutritional status with minimal adverse effects and drawbacks (BARROS, 1999).

In current times, it is noted that there is a great advance in the guarantee and the quality of the machines that make the hemodialysis treatment, thus, making the treatment more reliable. (DAUGIRDAS, 2003).

According to Daugirdas (2003), nursing is considered to be the group of professionals that most presents a direct participation in the process that covers hemodialysis, thus covering the performance and the performance of these professionals in the solution of possible complications that perhaps during treatment.

For Daugirdas (2003), the presence and occurrence of complications are considered high. It is observed that hemodialysis aims to revert not only or simply uremic symptoms, but has as its broader goal, to reduce the pertinent procedural complications and to reduce the risk of mortality. Because of this, professionals who work in nursing need to remain always contemporary, linked to current issues in order to ensure a treatment that is based on safety and efficacy, with the intention of guaranteeing quality in the treatment of chronic renal patients.

\section{METHODOLOGY}

The methodology used in this study concerns a literature review based on data from LILACS and SCIELO, in addition to contemplating other publications evaluated as being of great relevance in Brazilian territory. Whose methodological path followed, is based on the readings that required reflection, and exploration of the selected material.

The literary revision was carried out from August 2013 to February 2014. The following descriptors were used: hemodialysis, nursing work, patient and complications.

Initially, 26 previously researched articles were read. Then, we selected 16 articles that served as a basis for structuring this research.

In order to perform the analysis of the information studied, the data ordering was used, and the final analysis of the data was then classified, guided by the Minayo (2008) determinations.

Then, the analysis of the collected data adopted the thematic analysis technique. However, other important works were used which also served as support for the study in question (MINAYO, 2008).

Nursing workers working in the hemodialysis session were analyzed and used as inclusion criterion, as 
well as articles presented in full in the database used to make this research.

All the literature selected for the construction of this work has publications between the years of 1999 to 2013.

\section{RESULTS AND DISCUSSION}

Over the years there have been major changes in the role of nurses in the hemodialysis session. To demonstrate this, we searched for this study, bibliographic databases and online research focused on nursing, hemodialysis and nephrology study. Where several works were found including 16 articles, monographs and magazines that were selected presenting their publication in the period of 2004 to 2013, serving as a foundation for the realization of this research, with a diversified view of authors that direct their work to the role of the nurse in the the hemodialysis session.

The growth and increase of patients presenting renal problems demonstrate that hemodialysis treatment in Brazil has been increasing rapidly over time. It is known that many are the causes of renal attack, and some of the kidney diseases have their treatment without leaving serious consequences. However, other diseases have been shown to cause impaired renal function and to progress rapidly or slowly to chronic renal failure (JUNIOR, 2004).

At a later stage, it is known that the kidneys can no longer guarantee the normality of the patient's internal environment. The literature shows that studies indicate that patients with hypertension, diabetes mellitus or family history of chronic kidney disease are more likely to develop chronic kidney disease (JUNIOR, 2004).

\subsection{The importance of nursing in the treatment of hemodialysis}

Initially it is pertinent to report that it is in Administrative Rule 154 of June 15, 2004, the establishment of technical standards to effectively promote all operations related to Renal Replacement Therapy Services, as well as to establish norms for the organization of these establishments with the System Unified Health System (SUS) (BRASIL, 2004).

The creation of this Ordinance is of paramount importance in order to provide the efficiency of the work related to renal patient care.

It is also verified in the same Ordinance, that for every 35 patients, the Hemodialysis unit must offer a doctor who is a nephrologist, having the specialty degree registered in the Federal Medical Council; in addition to the presence of one nurse for every 35 patients, and must have training in dialysis recognized by the Brazilian Society of Nephrology Nursing, and one technician or nursing assistant for every 4 patients per hemodialysis shift (BRASIL, 2004).

In view of the above, nursing in the treatment of hemodialysis has great relevance in regard to the uninterrupted observation of patients in the period in which the hemodialysis session occurs, and nursing can help save lives and may also avoid possible complications which is the early and accurate diagnosis of intercurrences. 
Therefore, it is very important that the patient has extreme confidence in nursing professionals, and that there may be a mutual relationship between them. Certainly, the nursing team, faced with their professional role, needs to be helpful, attentive to patients and should always be alert to intervene when necessary in order to guarantee the patient's health of the hemodialysis treatment (MEDSI, 2003).

It is common to observe that the presence of complications is very large in the hemodialysis session. Therefore, hemodialysis seeks the reversal not only of uremic symptoms, but also the reduction of complications inherent in the procedure itself and the reduction of mortality risk (MEDSI, 2003).

In view of the presented context, it is understood that it is of the utmost importance that nursing professionals are always updating, studying and improving themselves more and more to offer the chronic renal patient a quality and humanized treatment with greater safety.

\subsection{The role of the nurse and a work focused on the care, education and prevention of patients in the hemodialysis session.}

The nurse in the exercise of his function in the hemodialysis session has some attributions, and this professional is responsible for making this sector curative in patients with permicarde, subclavian and femoral vein, in addition, the nurse has the task of connecting them to machine (OLIVEIRA, 2008).

It is important to know that nurses play the role of providing care to the patient in an integral way, contemplating it as a whole, creating a mutual relationship of trust and safety between patient and nurse, giving priority to the care necessary for their treatment.

It is also up to him to guarantee the correct use of materials and equipment, guiding, supervising and evaluating. Also taking care of the quality of the safety environment, looking for the comfort of the patient and the team.

It is essential and very important that nurses have, in addition to the scientific background, the competence and technical ability pertinent to their own professional office, it is necessary that they present and have knowledge and deepening of those aspects that consider the feelings and the real needs of patients in the treatment of hemodialysis (OLIVEIRA, 2008).

The objective of nursing care in this sector is to identify and monitor the adverse effects of hemodialysis and complications arising from the disease itself, developing educational actions of promotion, prevention and treatment (OLIVEIRA, 2008).

A relevant fact to be analyzed by nurses refers to the patient's education regarding the charges determined by the treatment, since a deeper knowledge about their illness, treatment and possibilities of rehabilitation can assist them in coping with situations that cause daily stress hemodialysis (BARBOSA, 2010).

Thus, it is noted that the nurse in the exercise of his professional role, must constitute educational actions to cause a treatment aiming at quality and efficiency in the form of benefit to the patient, performing a prevention work when possible treat the complications. It should offer a service that is humanized, treating the patient globally and meeting their basic human needs so that it satisfies the patient within the presented needs. 
As it is known, the nurse performs a work directly with the patient, and because of this closer contact, the nurse is able to identify facial, verbal and nonverbal expressions in the session, can also verify obstacles, feelings of fear and doubts and the treatment the patient is undergoing.

Given this, it is proven that dialogue and observation in a more detailed and clinical way are essential for the identification of these factors and that certainly contribute to a better patient / nurse interaction, since they provide a relation of affection and active communication, making that the patient experiences and accepts in a better way his chronic illness and the session of hemodialysis that undoubtedly is fundamental for its treatment.

It is important to point out that it is the duty of the nurse to educate in health not only in patients, but also in the family, and to expand to the nursing team itself. This action by the nurse must be something constant and done in a structured way. The educational action gives patients and their families a better understanding and acceptance of procedures and trust in the multiprofessional team, teaching them to adapt to this new reality in order to learn how to live together in the most natural way possible.

Thus, it is concluded that the nurse must create tactics or mechanisms specific and specific to the chronic renal patient on hemodialysis, according to the need presented in each patient, in order to promote the care and consequently the reestablishment of the patient.

It is recognized that the whole Systematization of Nursing Assistance (SAE) is undoubtedly an apparatus that benefits the identification of these strategies, and it is up to the nurses to have knowledge and applicability of the phases in the nursing process.

\subsection{The nurse in the diagnosis of complications}

The complications that may arise during the hemodialysis session are: hypotension, muscle cramps, nausea and vomiting, chest and lumbar pain, fever and chills, acute pulmonary edema, imbalance syndrome, among others (FAVA, 2006).

The nurse plays a fundamental role in the diagnosis of complications during the hemodialysis session.

The following are some of the complications that commonly occur and which are part of the nurses' competence to identify them:

\subsubsection{Itching}

Commonly called itching, pruritus is the most important skin sign in uremic patients, which is diagnosed by the nurse in the hemodialysis session. It is also known that pruritus or itching is a common appearance in patients being treated. This is due to the toxic effect that uremia causes on the skin. Circulating uremic toxins are responsible for pruritus, which may disappear as the onset of hemodialysis treatment (RIELLA, 2003). It is important to remember that even with the treatment of hemodialysis pruritus does not always calm or alleviate, even risking the situation in which the patient is diagnosed with pruritus.

The finding of pruritus in some patients shows that the sensation is very latent and alive, resulting in abrasions on the skin, in the hemorrhagic crusts, in the pustules and also contributes to the formation of 
nodules in the patient. The lesions consist of the face, back, trunk and extremities of the patient who is pruritus, leaving them uncomfortable and even embarrassing (Calixto, 2003).

It is known that some treatments used in this complication are considered effective as an example the use of ultraviolet applications, the use of topical emollients based on camphor uses phosphate binders. The use of oral or intravenous antihistamines and parathyroidectomy is indicated for patients with osteoarthritis and severe hyperparathyroidism (CALIXTO, 2003). Treatment is important when performed effectively by using means considered reliable for treatment success.

\subsubsection{Nausea and vomiting}

In the hemodialysis sessions, it is very common for the nurse to identify the presence of nausea and vomiting, because they are complications that happen routinely being provoked by several factors. The large number of cases identified in stable patients may be linked to hypotension, but may also be an early onset of imbalance syndrome (CALIXTO, 2003).

Therefore, the initial indication is to perform the treatment of hypotension, in the finding of the same. But if nausea and vomiting still continue, then the use of an antiemetic to treat the problem is suggested. The truth is that it is extremely important to avoid hypotension during dialysis at any cost in order to avoid further harm to the patient. In some patients, a reduction in blood flow velocity by $30 \%$ during the first hour of dialysis may be beneficial. However, the treatment time should be prolonged proportionally (DAUGIRDAS, 2003).

\subsubsection{Arterial Hypotension}

It has been observed that the incidence of hypotension is a complication that occurs frequently in the hemodialysis process, and is actually a consequence of the large amount of fluid that is removed from the plasma volume during a daily dialysis session. (FERMI, 2010). The water accumulated in the Interdialytic interval is withdrawn directly by the ultrafiltration mechanism.

It is important to consider that other very common signs and symptoms observed relate to dizziness and the sensation of fainting, precordial pain, sweating, mental confusion and even tachycardia. The main causes of hypotension during the session are: excessive weight gain, hyponatremia, excessive ultrafiltration, use of antihypertensives during dialysis.

Treatment needs to be started immediately. The patient should be placed in the position of Trends remember, should be administered bolus of $100 \mathrm{ml}$ of SF at $0.9 \%$ or more if necessary, the ultrafiltration velocity should be decreased to the nearest possible zero, adequate oxygenation and control ideal of dry weight (FERMI, 2010).

If the hypotensive event is corrected, a cautious evaluation of the frequency and intensity of the occurrence is indicated so that new crises may be avoided. Nursing interventions such as rigorous monitoring of vital signs and observation of symptoms can help dramatically decrease the occurrence and intensity of hypotensive episodes in these patients (RIELLA, 2003).

In view of the previous presentation, it is noted that the treatment in hemodialysis is considered painful, 
exhausting and often suffering, generating shocking changes not only in the patient's life, but also of his relatives, inducing them to adopt different habits of life due to treatment and kidney disease.

Thus, it is understood that the hemodialysis session is of great relevance for the chronic renal patient, since it allows for a better quality of life. In this aspect, it is observed the importance of the role of the nurse in the hemodialysis session by means of actions that includes orientation for changing habits and customs, such as: adoption of a strict diet, with reduction of protein, sodium and potassium; limitation to work and physical activity and adherence to treatment routines, this information is of extreme necessity for the patient's well-being.

Another point to be considered in this process refers to the psychological factor of the patient who is compromised, because in view of the situation in which he / she is, he / she feels unable to perform some actions, thus contributing to undermine his / her self-esteem. As a result, the family plays a fundamental role in this phase of patient adaptation, which requires support and encouragement not to abandon treatment and to follow in a reliable and positive way.

\section{Conclusion}

The study was extremely important because it made possible a more contemplative investigation of the role of the nurse in the hemodialysis session, allowing the patient to know and identify the complications that make the treatment process difficult in hemodialysis.

It was noticed through the role of the nurse and his / her performance that the level of knowledge acquired by the patients through the practical information provided by the nurses complement each other by promoting means of applicability in the nurses' and the patient's work, hence the necessity and importance of that guidance and education be done so that the patient in fact increases his knowledge in the treatment for his own benefit.

It was verified that the care given by the nurse to the patient under treatment has a motivating and important character for the success of the treatment. It expects to obtain from this assistance the necessary subsidies for its improvement and well-being.

The results of this research revealed that the patients do indeed need the follow-up of the nurse, they need the importance of the role of this professional to better assist them in their difficulties, which are most often related to the fact that they can not relate the complications that occurred during the treatment session. The nurse has great importance in the diagnosis of the complications of the hemodialysis patient.

In view of all that has been exposed in this work, it is necessary to carry out new studies in order to understand the variables that emerged during its accomplishment, thus contributing to the enrichment of the materials available for study, and that will have as a final result a quality, safe nursing care for the patient during the hemodialysis session.

This study made it possible to identify the importance of the nurse in the hemodialysis treatment, both in the actions directly with the intercurrences and in the nurse-patient relationship, where the guidelines facilitate the adaptation of this to the new habit of life, through dialogue and attention given to it. 
It can be noticed that there is a shortage of papers written by nursing professionals, which may be related to the small number of research carried out by nursing in this area.

It is suggested that more work be researched and performed with this theme, because it is important to develop actions that actually contemplate the patient and to expand the work of the role of the nurse in the hemodialysis session.

\section{REFERENCES}

BARBOSA, G.S and VALADARES, G.C. Hemodialysis: lifestyle and patient adaptation. Acta paul. enferm., 2009, vol.22, no.spe1, p.524-527. ISSN 0103-2100

BARROS, E .; MANFRO, R.C .; THOMÉ, F. S., ... [etel]. Nephrology: routines, diagnosis and treatment. 2nd ed. Porto Alegre: Medical Arts, 1999.

CALIXTO RC, LORENÇON M, CORREAA MSMF, CRUZ AP, MARTINS LC, BARRETTI P, et al. Dialytic Intercurrences in Hemodialysis. J Bras Nefro 2003.

CARVALHO, M.E. Publication of the Advanced Nucleus of Nephrology and Dialysis of the Hospital Sírio-Libanês July / August / September - 2009 4th edition.

CESARINO C. B. CASAGRANDE L. D. R. Patient with chronic renal failure on hemodialysis treatment: educational activity of the nurse. Rev. Latino-Am. Nursing, 1998

CUPARRI, L. Nutrition guide: clinical nutrition in the adult. Barueri, SP: Manoel, 2002.

DALGIRDAS J.T. Dialysis manual. 3ª Ed. Rio de Janeiro (RJ): Medsi; 2003

LIMA A. F. C, Gualda Dulce Maria Rosa. Due oral history: seeking the meaning of hemodialysis for the chronic renal patient. Rev.c.enferm. USP. Sep 35 (3): 235-241. 2001

MACHADO, LRC and CAR, MR. The dialectic of the daily life of patients with chronic renal failure: between the inevitable and the casual. Rev. esc. sick USP, Sep 2003, vol.37, no.3, p.27-35. ISSN 0080-6234

MARTINS, C. Nutrition for hemodialysis patients. 3. ed. UFPR, 1999.

MINAYO M. C. de S, org. Social Research: theory, method and creativity. Petrópolis: Vozes; 1994.

MINISTRY OF HEALTH (BR). Hemodialysis: More Money to Extend Service. Brasilia DF); 2012. [acesso 2013 Ago 23], Available at: //portalsaude.saude.gov.br/portalsaude/noticia/4458/162/recursos-para-hemodialise-in-r\$-1816-mi.html.

NASCIMENTO C. D, MARQUES I. R. Nursing interventions in the most frequent complications during the hemodialysis session: literature review. Rev. bras. nursing. [periódico na Internet]. 2005 Dec;[24] 58 (6): 719-722. 2005 
OLIVEIRA, S.M et al. Elaboration of an instrument of nursing care in the hemodialysis unit. Acta paul. enferm., 2008, vol.21, no.spe, p.169-173. ISSN 0103-2100

PAOLUCCI, A.A. et al. Nephrology. Rio de Janeiro: Guanabara Koogan, 1977.

RIELLA, M. C. - Principles of Nephrology and Hydroelectrolytic Disorders, 4 ed. Rio de Janeiro, Guanabara Koogan, 2003.

ROMÃO JUNIOR, J. E. Chronic Renal Disease: Definition, Epidemiology and Classification. JBN; 26 (3 -Supl 1): p1-3.USP, São Paulo 2004.

[1] Graduated nurse in the city of Tucuruí-Pa. Concluded of the Course of Specialization in Nephrology of Faculty Machado de Assis / FAMA-PA.

[2] Biologist. PhD in Biological Sciences - Area of ??Genetic Concentration. Professor and Researcher at CESUPA - University Center of the State of Pará.

[3] Biomedical. PhD in Tropical Diseases. Professor and Researcher at the Federal University of Amapá, AP. Collaborating researcher at the Tropical Medicine Nucleus of UFPA (NMT-UFPA).

[4] $\mathrm{PhD}$ in Clinical Psychoanalysis, Researcher at the Center for Research and Advanced Studies.

[5] Biologist. Doctor in Theory and Research of Behavior. Professor and Researcher of the Federal Institute of Amapá - IFAP.

[6] Biologist. Doctor of Medicine / Tropical Diseases. Professor and Researcher at the Federal University of Pará - UFPA. Researcher at the Laboratory of Human and Environmental Toxicology and in the Laboratory of Oxidative Stress of the Nucleus of Tropical Medicine of UFPA (NMT-UFPA).

\section{PUBLIQUE SEU ARTIGO CIENTÍFICO EM:}

https://www.nucleodoconhecimento.com.br/enviar-artigo-cientifico-para-submissao 